\title{
Association of Wolff-Parkinson-White syndrome with congenital abnormalities of hands and feet
}

\author{
A. P. Niarchos ${ }^{1}$, R. Finn, H. N. Cohen, and N. J. Buch \\ From Royal Southern Hospital, Caryl Street, Liverpool
}

$A$ female patient, 56 years old, with type $A$ Wolff-Parkinson-White (WPW) syndrome and congenital skeletal abnormalities of the hands and feet is described. Though all four limbs were affected, the patient's main disability was caused by the defects of the right hand: this was short and hypoplastic, with hypoplastic phalanges, absent nails, syndactyly, and fibrous constriction rings on the fingers. She had no other evidence, apart from the WPW syndrome, of congenital heart disease. Chromosome studies were normal.

To our knowledge an association of the WolffParkinson-White (WPW) syndrome with congenital skeletal abnormalities of the hands and feet has not been previously described.

\section{Case report}

A female patient, 56 years old, was admitted in February 1973 because of a tachycardia associated with breathlessness for the past 24 hours. She gave a history of a similar episode, which occurred soon after the delivery of her daughter, in 1958, when the patient was $4 \mathrm{I}$ years old. Since then she had experienced short paroxysms of palpitation on several occasions, but these were not sufficiently prolonged to require any treatment. In addition she gave a history of having abnormalities of both hands and feet since birth (see below). There was no history of diabetes, angina, hypertension, or any other cardiac illnesses. The patient's mother had no illnesses during her pregnancy, had not taken any medication, and the delivery of her daughter (patient) was normal. A history of two sudden deaths was present in the family (see below).

\section{Cardiovascular system}

A regular tachycardia, $\mathrm{I} 86$ a minute, was present. There were no murmurs or other extra sounds. There was no evidence of cardiac hypertrophy. The jugular venous pressure was slightly raised, and fine basal crepitations were heard at the bases of the lungs. The blood pressure was $120 / 80 \mathrm{mmHg}$. The electrocardiogram revealed a nodal tachycardia of 187 a minute (Fig. I). A chest radiograph showed pulmonary oedema. Frusemide and

${ }^{1}$ Present address: Section on Hypertension, Henry Ford Hospital, 2799 W. Grand Blvd, Detroit, Michigan 48202, U.S.A. digoxin were given intravenously but the tachycardia eventually reverted to sinus rhythm with intravenous practolol. The electrocardiogram now showed a type A WPW syndrome (Fig. I). A second chest radiograph taken when the patient was in sinus rhythm showed resolution of the pulmonary oedema. The heart and lung fields were normal; there was no evidence of congenital heart disease.

\section{Skeletal abnormalities}

a) Clinical findings The right hand was the most severely affected (Fig. 2) of the four limbs, and accounted for most of her disability. The thumb was normal. A constriction ring was present at the base of the index finger which in addition had flexion deformity. Syndactyly and rudimentary phalanges with hypoplastic nails were present in the middle and ring fingers. Small pits were present in the dorsal and palmar aspects between these two digits. The middle phalanx of the little finger was rudimentary, and the nail was absent. On the left hand constriction rings were present at the base and middle of the middle phalanges of the index finger and middle finger. A constriction ring was present at the head of the middle phalanx of the ring finger. Hallux valgus was present on the right foot, the nail of the big toe was absent, the third and fourth toes were short and fused without nails, and the nail of the fifth toe was rudimentary. The big toe of the left foot was short with hallux valgus deformity, the second toe was short, and rudimentary nails were present on the fourth and fifth toes.

b) Radiological findings $\mathrm{A}$ radiograph of the right hand showed that the middle and distal phalanges of the third and fourth fingers were absent, while the distal phalanges of the index and little fingers were very 
hypoplastic. The fourth and fifth metacarpals were hypoplastic (Fig. 2). The terminal phalanx of the left middle finger was short. A radiograph of the right foot showed that the second and third phalanges of the second, third, fourth, and fifth toes, and the terminal phalanx of the big toe were absent, while the first phalanx of all toes except the big toe were hypoplastic. The left foot was clubbed with similar, but less severe abnormalities.

\section{Other abnormalities}

Hypertelorism, prognathism with widely spaced teeth, and high arched palate were present. The left calf was $3 \mathrm{~cm}$ thinner than the right.

\section{Laboratory tests}

A full blood count was normal. The maximal values of the SGOT and LDH were normal (15 and 62 international units, respectively). Blood glucose, urea, uric acid, and electrolytes were normal. Cholesterol and lipoprotein electrophoresis were normal. Chromosome analysis on peripheral blood was normal.

\section{Family study}

In spite of a history of sudden deaths from heart disease of the father and brother of the propositus at the age of 25 and 23, respectively, no further ininformation was available to confirm with certainty the type of heart disease. The mother of the propositus is 78 years old. Her chest radiograph and electrocardiogram are normal. The terminal phalanges of the middle and ring fingers are hypoplastic on the right hand, and the left thumb is somewhat elongated. Minor right hand abnormalities were probably present in the brother of the propositus. The daughter of the propositus is 15 years old and and perfectly healthy, her chest radiograph electrocardiogram being normal.

\section{Discussion}

It has been well established that the WPW syndrome is due to the presence of a congenital anomalous and accessory atrioventricular pathway. The evidence for this concept is based on electrocardiographic data, experimental studies, observations during cardiac catheterization and atrial pacing, and histological studies. All this evidence was discussed in detail by Schamroth (I97I). In addition data from His bundle electrograms (Castillo and Castellanos, I970; Roelandt et al., I973), and reports of successful surgical interruption of the bundle of Kent (Cobb et al., I968) support this concept. Furthermore, the even distribution of the WPW syndrome in all age groups, its presence in children and newborn infants, and its familial incidence and association with other forms of congenital heart disease, strongly support a congenital origin (Schamroth, I97I). It is very unlikely that the coexistence of the WPW syndrome and skeletal abnormalities in our case was due to a mere coincidence, since the incidence of the syndrome has been estimated as $\mathrm{I} \cdot 6$ per thousand in the normal population (Averill, Fosmoe, and Lamb, 1960), while hand abnormalities were recorded in less than I per cent of 430

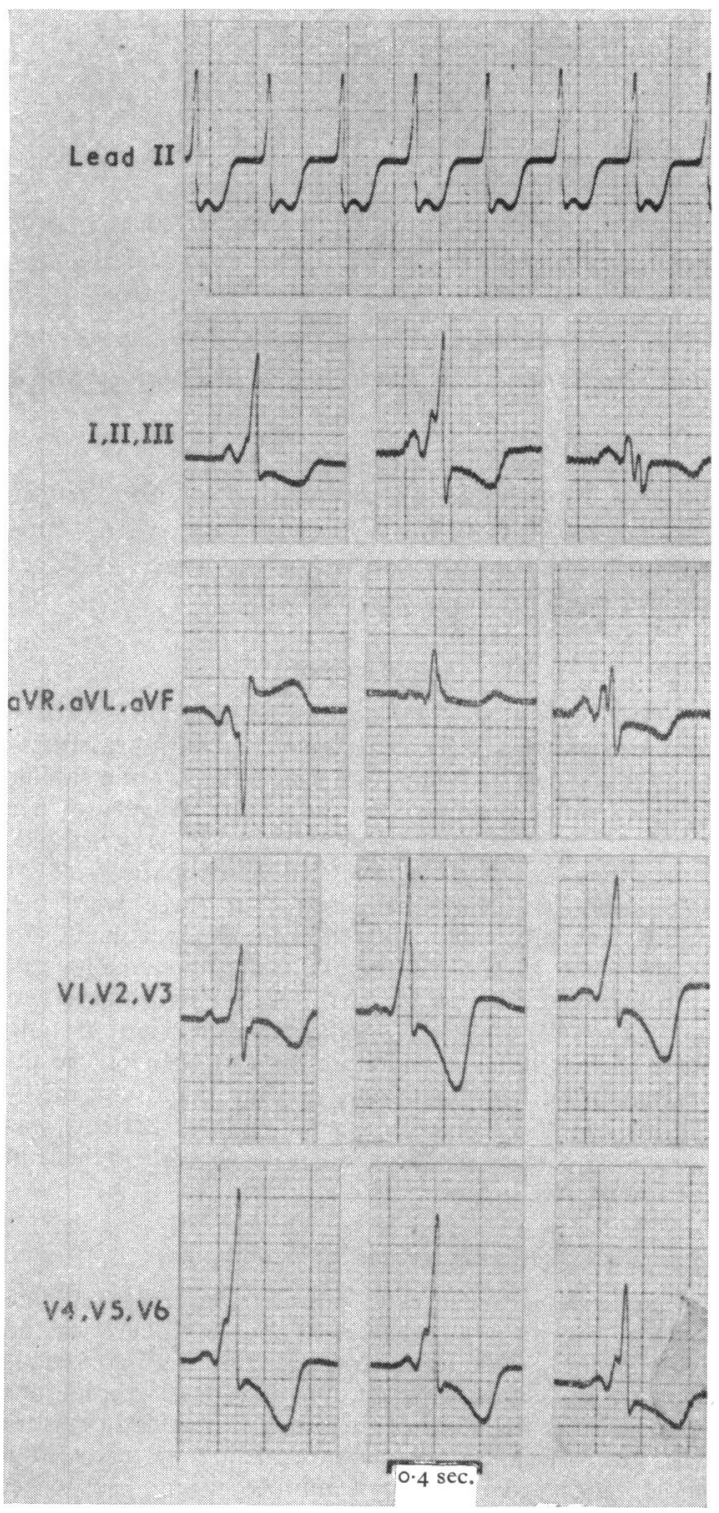

FIG. I Electrocardiogram showing nodal tachycardia and type $A$ Wolf-Parkinson-White syndrome. 


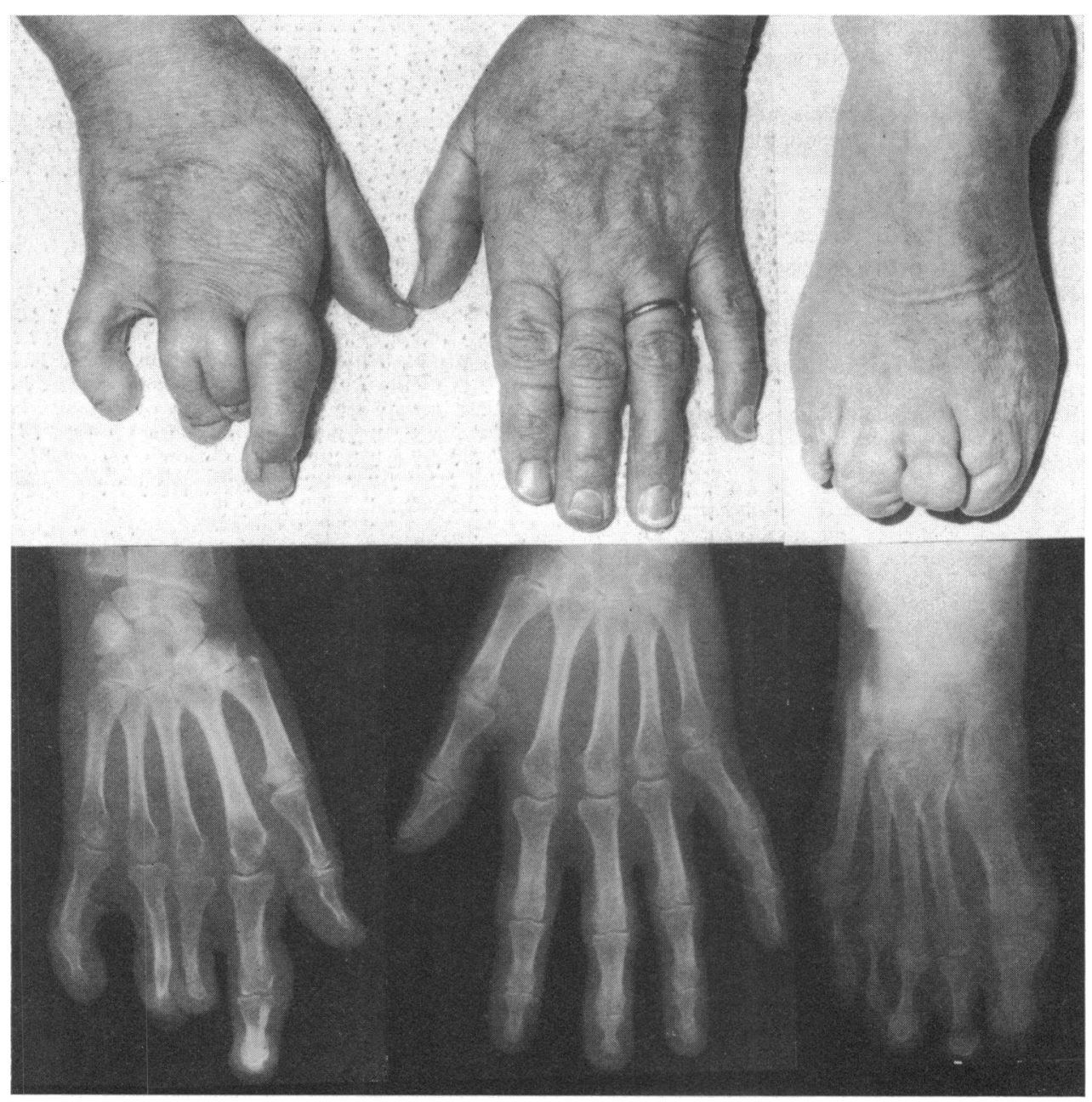

FIG. 2 The right hand is small with hypoplastic fingers and nails. Syndactyly and constriction rings are present. Hypoplastic toes are present on the right foot. For details, see text.

consecutive newborn infants with musculoskeletal deformities but without heart disease (Bick, 1960).

The aetiology of most congenital defects, including cardiac, is not known. Chromosomal analysis was normal in our patient. Normal chromosome studies, however, do not exclude a partial deletion or inversion, changes which cannot be detected with present techniques. It is of interest, that, not only in this case but also in the wellestablished cardiovascular-sekeletal syndromes (Holt and Oram, 1960; McKusick, 1966; Emanuel, 1970; Krikler, 1973; Neill, 1972), the hands are most commonly and more severely affected, while the feet are very infrequently affected, and when so, show very minor defects. An embryological explana- tion has been suggested for this preferential involvement by Holt and Oram (1960). The limb buds appear in the embryo during the fourth week, at the time when the primitive heart tube is beginning to differentiate, and the main development of both limbs and heart takes place simultaneously in the next two weeks. The upper limb buds appear first and their growth is completed earlier than that of the lower limbs (Arey, 1965).

The present case certainly has a similar distribution of skeletal abnormalities, but whether it should be considered as a variant of the cardiovascular-skeletal syndromes, in which the congenital heart lesion is the anomalous atrioventricular pathway, is too early to predict; the hypothesis is 
nevertheless under investigation in a larger group of patients with the WPW syndrome.

We are very grateful to Dr. S. Walker of the Cytogenetics Unit of the University of Liverpool for the chromosome studies.

\section{References}

Arey, L. B. (1965). Developmental Anatomy, 7th ed. W. B. Saunders, Philadelphia and London.

Averill, K. H., Fosmoe, R. G., and Lamb, L. E. (I960). Electrocardiographic findings in 67,375 asymptomatic subjects. IV. Wolff-Parkinson-White syndrome. American fournal of Cardiology, 6, 108.

Bick, E. M. (1960). Congenital deformities of musculoskeletal system noted in the newborn. American fournal of Diseases of Children, 100, 861.

Castillo, C. A., and Castellanos, A., Jr. (1970). His bundle recordings in patients with reciprocating tachycardias and Wolff-Parkinson-White syndrome. Circulation, 42, 271.

Cobb, F. R., Blemenschein, S. D., Sealy, W. C., Boineau, J. P., Wagner, G. S., and Wallace, A. G. (1968). Successful surgical interruption of the bundle of Kent in a patient with Wolff-Parkinson-White syndrome. Circulation, 38, IOI8.

Emanuel, R. (1970). Genetics and congenital heart disease. British Heart fournal, 32, $28 \mathrm{r}$.

Holt, M., and Oram, S. (1960). Familial heart disease with skeletal malformations. British Heart fournal, 22, 236.

Krikler, D. M. (1973). The cardiovascular system. In Clinical Genetics, 2nd ed., p. 409. Ed. by A. Sorsby, Butterworths, London.

McKusick, V. A. (1966). Heritable Disorders of Connective Tissue, 3rd ed. C. V. Mosby, Saint Louis.

Neill, C. A. (1972). Etiology of congenital heart disease. In Pediatric Cardiology, Cardiovascular Clinics, 4: No. 3, p. 137. Ed. by M. A. Engle. Davis, Philadelphia.

Roelandt, J., Schamroth, L., Draulans, J., and Hugenholtz, P. G. (I973). Functional characteristics of the WolffParkinson-White bypass. A study of six patients with His bundle electrograms. American Heart fournal, 85, 260.

Schamroth, L. (1971). The Disorders of Cardiac Rhythm, p. 233. Blackwell Scientific Publications, Oxford and Edinburgh.

Requests for reprints to Dr. A. P. Niarchos, Section on Hypertension, Henry Ford Hospital, 2799 W. Grand Blvd, Detroit, Michigan 48202, U.S.A. 